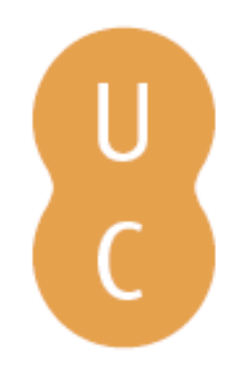

\title{
nombalina
}

Palcos do olhar: uma «mise-en-scène royale» sob Richelieu (Mirame, tragi-comédie)

Autor(es): $\quad$ Anacleto, Marta Teixeira

Publicado por: Imprensa da Universidade de Coimbra

URL

persistente: URI:http://hdl.handle.net/10316.2/38710

DOI: $\quad$ DOI:http://dx.doi.org/10.14195/978-989-26-1164-8_33

Accessed : $\quad$ 26-Apr-2023 12:41:50

A navegação consulta e descarregamento dos títulos inseridos nas Bibliotecas Digitais UC Digitalis, UC Pombalina e UC Impactum, pressupõem a aceitação plena e sem reservas dos Termos e Condições de Uso destas Bibliotecas Digitais, disponíveis em https://digitalis.uc.pt/pt-pt/termos.

Conforme exposto nos referidos Termos e Condições de Uso, o descarregamento de títulos de acesso restrito requer uma licença válida de autorização devendo o utilizador aceder ao(s) documento(s) a partir de um endereço de IP da instituição detentora da supramencionada licença.

Ao utilizador é apenas permitido o descarregamento para uso pessoal, pelo que o emprego do(s) título(s) descarregado(s) para outro fim, designadamente comercial, carece de autorização do respetivo autor ou editor da obra.

Na medida em que todas as obras da UC Digitalis se encontram protegidas pelo Código do Direito de Autor e Direitos Conexos e demais legislação aplicável, toda a cópia, parcial ou total, deste documento, nos casos em que é legalmente admitida, deverá conter ou fazer-se acompanhar por este aviso.

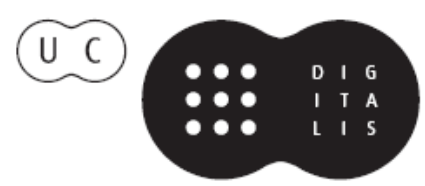


Marta Teixeira Anacleto

Universidade de Coimbra / Centro de Literatura Portuguesa

\section{PALCOS DO OLHAR: UMA «MISE-EN-SCÈNE ROYALE» SOB RICHELIEU (MIRAME, TRAGI-COMÉDIE)}

No âmbito da evolução da dramaturgia francesa clássica e da oscilação ontológica constante a que os géneros estiveram sujeitos no Grand Siècle, a tragi-comédie teve o seu apogeu, de acordo com a maior parte dos críticos, entre 1630 e 1640/501. A essa instabilidade estética e ao forte impacto assumido pela forma no palco francês, não será eventualmente alheia a "crise da modernidade» de que é sintoma primordial²: não só esse momento peculiar do século acompanha o debate teatral dos anos 1628-1640, como o questionamento intrínseco de conceitos-chave como "prazer» e "verosimilhança", na sua ligação à Antiguidade e a uma leitura particular dos Antigos, atinge particular expressividade no âmago de uma poética teatral radicada na ambivalência que condiciona a própria designação genológica em causa. Por isso, a tragi-comédie, género marcadamente moderno, acaba por se encontrar no centro de um grande debate teórico e estético que é também o debate dos minores na época. Infere-se, assim, que esse modelo formal cristaliza uma das reflexões estéticas essenciais do século XVII, relacionada com a complexa exegese aristotélica e a estética da imitação absoluta, correspondendo a um momento de fratura, de passagem de uma conceção de representação a uma conceção de imitação ${ }^{3}$.

\footnotetext{
1 Ver, entre outros: Roger Guichemerre, La tragi-comédie, Paris, PUF, 1981; Charles Mazouer, Le théâtre français de l'âge classique I-Le premier xvII siècle, Paris, Champion, 2006.

2 Ver Hélène Baby, La tragi-comédie de Corneille à Quinault, Paris, Klincksieck, 2001.

3 Baby, 2001, p. 272.
} 
Destacam-se, nesse espaço temporal, as peças de Hardy, Corneille, Scudéry, Desmarets de Saint-Sorlin, Du Ryer, Mareschal, Pichou, Rotrou, Rayssiguier, para surgirem, depois, com alguma vitalidade, no período do pós-Fronda, textos de autores como Claude Boyer, Chappuzeau, Catherine Desjardins e Quinault. Sintomaticamente, para este conjunto heterogéneo de autores, Roger Guichemerre ensaia uma definição que poderá ser retida: «une action dramatique souvent complexe, volontiers spectaculaire, parfois détendue par des intermèdes plaisants, où des personnages de rang princier ou nobiliaire voient leur amour ou leur raison de vivre mis en péril par des obstacles qui disparaîtront heureusement au dénouement.»" A essa definição associa, igualmente, o crítico um esquema morfológico (intrigas de amores contrariados, de palácio, com obstáculos, crises de fidelidade/inconstância, reconquista/renúncia, desespero/luta; desenlace feliz com eliminação dos adversários, reconhecimentos, justificações, arrependimentos), uma tipologia de personagens (amantes, rivais, pais, reis tiranos, maus conselheiros, príncipes disfarçados, soldados, homens de albergues, criados irónicos, personagens ridículas), um temário exaustivo e consequentes circunstâncias da ação (amor súbito, irresistível, contrariado; desesperos que conduzem ao suicídio ou à loucura; violência e vingança amorosas; pais ou filhos perseguindo um sedutor; pais e filhos rivais; mulheres abandonadas; ódios familiares; raptos; tentativas de violação; duelos; conflitos provocados pelo amor; o disfarce, travestis e sentimentos fingidos). A forma é definitivamente um puzzle dramático de perfil romanesco que, à partida, radica no jogo instável entre ilusão e vraisemblance que o teatro do Grand Siècle nunca pretendeu escamotear, mesmo (e sobretudo) na escrita institucional das Poéticas.

De notar, desde logo, que o triunfo dessa forma compósita sob Richelieu e no Hôtel de Bourgogne, trabalhada simultaneamente por autores «maiores» e por autores «menores» (de acordo com uma definição tradicional ou razoável do cânone), bem como a dificuldade de o associar a uma praxis aristotélica, justifica porventura a ausência de textos teóricos sobre o género, exceção feita ao prefácio que François Ogier redige, contra os Antigos, para Tyr et Sidon de Jean Schélandre (1628)5. A verdade é que existe explicitamente, por parte de

4 Guichemerre, 1981, p. 15.

5 François Ogier, "Préface au Lecteur» in Giovanni Dotoli, Temps de Préfaces. Le débat théâtral en France de Hardy à la Querelle du "Cid», Paris, Klincksieck, 1996, p. 181-191. 
autores e teóricos, a consciência de um virtuosismo da forma (ou de uma potencial teatralidade), ancorada na procura sistemática das emoções, no culto de um hibridismo formal inequívoco, numa "movência» ligada à inventio romanesca e à dispositio irregular ou descontínua, à substituição do phobos moral aristotélico pelo «suspense» ficcional. Por isso, a tragi-comédie é marcada pelo estigma da rutura, da oscilação entre legitimidade e ilegitimidade teóricas que acompanham o modo de escrita dos textos. Como demonstra Hélène Baby em artigo de $2004^{6}$, a situação da tragi-comédia no tempo de Richelieu não é linear: ao mesmo tempo em que apenas Hardy vê reconhecida, com alguma legitimidade, a representação das suas peças, a tragi-comédia é um dos principais instrumentos da renovação moderna do teatro e da releitura do modelo aristotélico. Assim, este movimento de contornos oximóricos ilustra o status destes textos-espetáculo que recuperam constantemente uma sintaxe do romanesco, sem alcançarem uma garantia trágica e teórica, e permanecendo numa exterioridade que será apanágio dos menores. Esse expressionismo de um teatro que "cherche avant tout à parler aux yeux, à l'imagination et à la sensibilité du public par l'importance qu'il accorde au spectacle et au pouvoir suggestif des mots» é, afinal, uma manifestação expressiva da teatralidade paradoxal que fundamenta o modo de ser da tragi-comédie, ultrapassando as regras para se conformar à organização institucional, estética e moral de Richelieu.

É, ainda, no âmbito do paradoxo do clair/obscur tipicamente barroco, através do qual Christian Jouhaud lê a relação entre literatura e poder ${ }^{8}$, e da sua aplicação verosímil ao campo estético da tragi-comédia, que o jogo entre o alegórico e o político se desenvolve sob Richelieu (e após Richelieu, com Mazarin e Louis XIV), legitimando-se o género como um "mineur» simbolicamente vigiado: os seus atores são "des Comédiens du Roi» que atuam com a máscara aristocrata ou real para o prazer dos espectadores. O que está, então, em causa é a modernidade de um género que é apreendida como tal por Richelieu, ao tirar constantememente partido das «nouveautés» de uma escrita dramática e de um espetáculo que se constrói perante o olhar do público, integrando uma metareflexão sobre/

"Hélène Baby, "De la légitimation paradoxale: la tragi-comédie au temps de Richelieu", Littératures Classiques - Le Théâtre au XVIIe siècle: pratiques du mineur, n ${ }^{\circ}$ 51, été 2004, p. 287-303.

7 Guichemerre, 1981, p. 174-175.

8 Ver Christian Jouhaud, Les pouvoirs de la littérature. Histoire d'un paradoxe, Paris, Gallimard, 2000. 
do político: a tragi-comédie é campo de ação de grandes senhores, dos reis, e da teatralidade das suas ações, o veículo preferencial da ideologia do heroísmo monárquico, de uma «teleologia política» ou de uma propaganda política cultural.

É nesta sequência que a fundação da Academia Francesa, da "Société des Cinq Auteurs» e a construção do teatro do Palais-Cardinal, inaugurado em janeiro 1641, com Miriame, tragi-comédie encomendada pelo Cardeal a Desmarets de Saint Sorlin, estão ligadas ao género tragi-cómico. Disso nos dá conta o início da epístola "Au Roy» que antecede o texto de Desmarets:

Bien que l'usage des triomphes publics semble estre aboly par toute la terre, la France a maintenaint un lieu où j'espere que vostre Majesté triomphera souvent, par les vers et les beaux spectacles que vostre grand Ministre y fera faire pour celebrer vos conquestes. (p. 43)

A ordem sociopolítica da corte é, por conseguinte, como que transposta para o espetáculo, para uma festa dos sentidos e, sobretudo, para uma festa do olhar que funciona sob o olhar do rei ou de Richelieu, como Mirame o ilustra. Do jogo de olhares e do prazer da perceção forma-se uma dupla alegoria: a alegoria do político e a do espetáculo tragi-cómico. Aliás, basta pensar no texto de Chapelain encomendado por Richelieu sobre o Cid e a regra das vinte e quatro horas "Lettre sur la règle des vingt-quatre heures» -, para entender que existiu um paralelismo formal entre a teorização da arte dramática e os modelos políticos (ou um modelo político), do qual resultou uma determinada evolução da teatralidade e da arte cénica. As considerações que Chapelain tece sobre a verosimilhança e a imaginação do espetáculo, os seus efeitos sobre o espírito dos espectadores, levam a crer que, na época (1630-1640), a arte dramática é um locus teórico onde é pensado o papel do espectador e o modo de persuasão do mesmo.

Mirame. Tragicomedie é, parece-me, um dos paradigmas dessa teatralidade política $^{10}$. E, ao encomendar o texto a Desmarets de Saint-Sorlin para a "Ouverture du Theatre de la Grande Salle du Palais Cardinal», Richelieu mostra compreender,

9 A edição citada será sempre a excelente e recente publicação editada por Catherine Guillot e Colette Scherer: Desmarets de Saint-Sorlin, Mirame. Tragi-comédie, Rennes, Presses Universitaires de Rennes, Coll. Textes Rares, 2010.

10 Veja-se, a este propósito, o pertinente capítulo "Service de Desmarets de Saint Sorlin", integrado na obra já citada de Christian Jouhaud (Jouhaud, 2000, p. 269 ss). 
sem ambiguidades escondidas, o âmbito e alcance do poder desta captatio da poesia dramática, de uma poesia dramática compósita que ia ao encontro do seu gosto pelos «jeux d'esprit» e pela linguagem «précieuse». Pellisson mostra-o claramente na sua Histoire de l'Académie Françoise (1652):

Comme il ne faut bien souvent pour donner le branle à tout un royaume, qu'un seul homme, quand il est élevé aux premiers rangs, la passion que le Cardinal avoit pour la poésie dramatique l'avoit mise en ce temps-là, parmi les François, au plus haut point où elle eût encore été. Tout ceux qui se sentaient quelque génie ne manquaient pas de travailler pour le théâtre: c'était le moyen d'approcher les grands, et d'être favorisé du premier ministre, qui, de tous les divertissements de la Cour, ne goûtait presque que celui-là.."

Desmarets de Saint-Sorlin, "Conseiller du Roi et Contrôleur général de l'extraordinaire des guerres", está ao serviço de Richelieu desde 1634, é precetor do seu sobrinho-neto, Armand de Vignerot, e são-lhe cometidos vários cargos político-literários pelo Cardeal: é um dos primeiros membros da Academia Francesa, seu cancelário durante quatro anos e escolhido para o grupo de comissários a quem cumpre analisar o Cid e as Observations de Georges de Scudéry. Desmarets é autor de um importante romance histórico, Ariane (1632), que manteve êxito indiscutível até ao século xviII, do longo Discours de la poésie à Monseigneur le Cardinal-duc de Richelieu e torna-se o dramaturgo favorito de Richelieu, apesar de a crítica contemporânea não ter investido muito, até agora, no estudo da sua figura singular. Talvez, porém, essa menoridade exegética se justifique na medida em que, para o autor, a escrita dramática não tinha sentido fora do contexto político, como fica demostrado pelos diferentes paratextos das suas obras. Les Visionnaires, comédia escrita em 1637, é a sua peça mais conhecida que obteve êxito incondicional, passando por "divertissement populaire», como o autor refere no "Argument, conciliando argutamente essa vertente com o serviço a Richelieu, ainda que a obra seja considerada como uma comédia «mineure" (tal como as de Scarron, Boisrobert, Tristan l'Hermite, Dancourt, Regnard,

11 Pellison et d'Olivet, Histoire de l'Académie Française, t. I, Genève, Slatkine Reprints, 1989, p. 81. 
Thomas Corneille) face às de Molière ${ }^{12}$. O dramaturgo fez representar igualmente outras tragi-comédias - Scipion, Roxane, Érigne - que refletem a legitimação estética da prática do tragicómico pela sua ligação política ao Cardeal: Roxane, por exemplo, terá uma importância política capital em termos de receção, já que analisa a razão política dos homens públicos e as paixões particulares, com um cenário histórico facilmente identificável com o de Louis XIII.

O significado alegórico e político da representação de Mirame torna-se, assim, determinante no âmbito da ideologia do heroísmo monárquico sujacente à tragi-comédie. Daí que Ludovic Celler, no século xix, considere que «la représentation de Mirame fut plus qu'un évènement littéraire ${ }^{13}$. A afirmação, integrada numa obra onde se analisa o teatro francês entre 1615-1680, aponta para o acontecimento literário, cultural, político que representou a estreia de Mirame, em janeiro de 1641, como espetáculo encomendado por Richelieu para a inauguração da grande sala do Palais-Cardinal e para ornamentar o casamento da sua sobrinha com o duque de Enghien. A mesma lógica encontra eco na leitura que Hélène Baby faz do evento, no quadro da legitimação do literário sob Richelieu, revelando, na argumentação implícita, o poder político de um «menor»: «Mirame, fastueuse production que Richelieu lui a commandée [à Desmarets], peut être considérée comme exemplaire du sort réservé à la tragicomédie, genre mineur pris entre les deux feux de la majoration politique et littéraire» ${ }^{14}$.

Entende-se, deste modo, que a inauguração daquele que é considerado um dos primeiros teatros modernos é concebida pelo recurso a uma representação alegórica, de contornos romanescos, focalizando-se sobre um discurso político que serve a modernidade absolutista para a qual tende Richelieu. Trata-se, com efeito, de um produto mundano, luxuoso, destinado a um público devidamente selecionado que se encontrava aberto à conciliação dos efeitos romanescos com os efeitos visuais do espetáculo, como o demostramam as cinco magníficas "planches" concebidas por Stefano Della Bella, gravador italiano da escola florentina renascentista que se havia instalado em Paris, em 1639, a pedido do

\footnotetext{
12 Ver a este propósito: Sternberg, Véronique, «La comédie des contemporains de Molière: une production mineure?", Littératures Classiques - Le Théâtre au xvIIe siècle: pratiques du mineur, n 51, été 2004, p. 171-185.

13 Leclerc, Ludovic (Celler), Les décors, les costumes et la mise en scène au xvIIe siècle (1615-1680), Genève, Slatkine Reprints, 1970, p. 17.

14 Baby, 2004, p. 297.
} 
Cardeal, seu protetor. Tais gravuras ${ }^{15}$, não só reconstituem o movimento cénico dos atores, associado a uma dinâmica romanesca, como também permitem visualizar o cenário do Palais-Cardinal e observar como o espectador deveria ser surpreendido e maravilhado. A própria cortina da boca de cena é concebida como instrumento de surpresa e êxtase.

O título da primeira edição aponta, desde logo, para estas condições excecionais de representação - Ouverture du théâtre de la grande salle du Palais-Cardinal - Mirame, tragi-comédie -, e adianta uma ligação estreita entre as gravuras de Della Bella, onde se adivinha o cenário, os jardins do palácio real de Héraclée em Bythynie, e a ação romanesca/dramática propriamente dita. Mesmo no texto publicado, a construção do espetáculo depende materialmente da imagem, do reflexo da intriga na gravura, que transporta também o leitor (na esteira do espectador) para o domínio da mimese pictural. A esta modernidade e à modernidade do espaço que acolhe a representação, deve acrescentar-se uma outra igualmente significativa: a do próprio autor, considerado por Marc Fumaroli, no ensaio exemplar "Les abeilles et les araignées», um Moderno, antes de Perrault ou de Fontenelle ${ }^{16}$.

$\mathrm{Na}$ realidade, ao conjugar elementos romanescos com efeitos cénicos de algum modo surpreendentes e que devem surpreender o público do Palais-Cardinal, Mirame antecipa o efeito das "machines-lumière» que Hélène Visentin ${ }^{17}$ entende serem fundamentais para a teatralidade inerente ao «théâtre avec machines» da segunda metade do século: de L'Inconnu de Donneau de Visé, Circé de Thomas Corneille, La Fête de Vénus de Claude Boyer, Le Nouveau festin de pierre de Rosimond, a Andromède, La Toison d'Or de Corneille, Les Amours de Vénus et d'Adonis e Les Amours du Soleil de Donneau de Visé. Não é, por isso, inocente a conjugação de fatores romanescos por vezes com reflexos intertextuais de L'Astrée (falsas mortes por envenenamento ou desmaio, mistério das identidades, disfarces, cruzamentos políticos e passionais, encontros e desencontros patéticos, batalha

15 As gravuras encontram-se reproduzidas ao longo da edição escolhida de Mirame e encontram correspondência com o início de cada Ato (Desmarets de Saint-Sorlin, Mirame. Tragi-comédie, 2010).

16 Ver capítulo «Une carrière de publiciste 'moderne': Jean Desmarets de Saint-Sorlin» inscrito em Marc Fumaroli, «Les abeilles et les araignées» in Fumaroli, Marc (ed.), La Querelle des Anciens et des Modernes, Paris, Gallimard, 2001,p. 105-129.

17 Ver o artigo fundamental de Hélène Visentin, "Le théâtre à machines: succès majeur pour un genre mineur", Littératures Classiques - Le Théâtre au XVIIe siècle: pratiques du mineur, $\mathrm{n}^{\circ} 51$, été 2004, p. 205-222. 
naval, cena final de revelações de identidades e casamento de Mirame e Arimant aprovado pelo Rei), com uma tipologia da ação que assenta em personagens emblemáticas do mundo político e do poder: le Roi de Bithynie; Mirame, Princesse de Bithynie; Almire, Princesse confidente de Mirame; Arimant, Prince favori du Roi de Colchos; Azamor, Roi de Phrygie; Acaste, Connectable de Bithynie, Adraste, Prince sujet du Roi de Bithynie; Ambassadeur du Roi de Colchos, entre outras.

Assim, desde a primeira cena de exposição, Desmarets associa a figura de autoridade do pai de Mirame, Roi de Bithynie, à irreverência da princesa que não aceita a paixão de Azamor porque ama Arimant, com quem se vê impedida de casar dado que este não possui sangue aristocrata/real ${ }^{18}$. Em longa cena com a confidente Almire, Mirame confessa os seus remorsos face ao pai e ao país, ainda que, na mesma lógica, ceda à tentação do romanesco aceitando um encontro noturno com Arimant congeminado pela confidente ${ }^{19}$. O diálogo entre os amantes é sinal dessa transposição escritural do paradigma romanesco de L'Astrée para o poema dramático tragicómico:

\begin{abstract}
ARIMANT.
Encore que des Roys soient autheurs de mon sang,

Tout mon espoir s'esteint, pensant à vostre rang.

Mais par mon seul amour mon espoir ressuscite:

Car l'excès en amour fait l'excès du mérite.

Un Pére ne veut pas que je sois vostre espoux:

Mais Amour qui le veut est le pere de tous. (...)
\end{abstract}

\title{
MIRAME
}

Mon coeur vous suit par tout, esclave volontaire;

Et me vouloir ravir, c'esr me vouloir desplaire (p. 81)

Também sinal dessa apropriação do romanesco pela dinâmica teatral de um espetáculo estético-político é a exploração da sequência de peripécias,

\footnotetext{
18 «LE ROY: Aymez donc Azamor, puis que je vous l'ordonne. / MIRAME: Mais qui n'a plus de coeur ne peut aymer personne.» (p. 56).

19 "ALMIRE: Criagnez-vous les tesmoins durant une nuict sombre? / Les voiles de la nuict cachent tout de leur ombre.» (p. 67); "MIRAME: Je veux donc bien le voir: il se faut retirer.» (p. 69).
} 
acompanhadas de efeitos de maquinaria, ainda embrionários, mas já sintomáticos de uma simbiose excecional de linguagens: após a vitória naval de Azamor sobre Arimant e da prisão deste último, o drama explora a perspetiva de os dois amantes serem separados e afastados um do outro, o que desencadeia confissões "généreuses» ${ }^{20}$ e pulsões de morte que resultam na falsa morte de ambos anunciada ao Rei. O «happy-end» conveniente à tragi-comédie e à inauguração de uma sala que se pretendia tornar o espelho do poder de Richelieu é sintomaticamente conseguido pela introdução de um embaixador do Rei de Colchos, com função de deus ex-maquina, que revela ser Arimant irmão de Azamor e, portanto, de sangue real, o que, após reconhecida como falsa (ilusória) a morte dos amantes, legitima o casamento:

MIRAME.

Ah! Quel excez de gloire?

Ceder à son rival le prix de la victoire,

Et mesmes en vivant: le voulez-vous grand Roy?

LE ROY.

Puisqu'un amour constant engage vostre foy,

Qu'Azamor y consent, qu'Arimant est son frere,

Qu'il herite d'un sceptre, il vous faut satisfaire

MIRAME.

Ah! Pere sans exemple!

Ah! Prince genereux!

LE ROY.

Que l'on deslivre Arbas; allez, vivez heureux. (p. 166)

Sob uma intriga romanesca complexa e efeitos de espetáculo que insistem sobretudo na sucessão surpreendente do dia e da noite, respeitando um lugar

20 «MIRAME: Porveu que vous viviez je vaincray tous obstacles. / Amour pour vous servir me promet des miracles. / Quoy qu'on puisse opposer j'en viendray bien à bout.» (p. 112). 
único, Desmarets de Saint-Sorlin denuncia as intrigas do partido espanhol para sublinhar o triunfo do Ministro de Louis XIII. De acordo com a leitura arguta de Françoise Siguret, o dramaturgo hipostasia a alegoria para reforçar o poder do teatro (leia-se, da sala de teatro, do palco) e o poder individual de Richelieu: o olhar, sobretudo o "olhar do príncipe» que está no cume da pirâmide estabelece o elo especular desejável entre o rei-ator e o rei-espectador, entre o que faz a entrada solene em palco e o que observa, diante de si próprio, o funcionamento da ordem monárquica e a sua representação, existindo um movimento de deslocação constante que faz do teatro - Siguret cita D'Aubignac - «le lieu où l'on regarde ce qui s'y fait ${ }^{21}$, isto é, o lugar onde a ação romanesca de Mirame se associa, de forma plástica, aos factos da História.

Refletindo o duplo prazer da representação e da ação que é apanágio da tragi-comédia ${ }^{22}$, Mirame constitui, assim, uma operação política de que dão igualmente conta decorações e maquinaria que acompanharam essa intriga romanesca recheada de reis e príncipes, histórias de mistérios e revelações. Não só Richelieu pretendeu que esta fosse a primeira peça representada sob sua proteção com a presença de um arco de proscénio onde se encontravam máquinas que representavam o sol e a lua, para fazer face à maquinaria italiana, como o cenário, submetido ao movimento dos astros, mostra um jardim de um palácio com o mar e barcos ao longe («La Scene est dans le jardin du Palais Royal d'Heraclée, regadant sur la mer» - p. 45), forjado por Jean Lemaire, pintor do rei para a Grande Salle do Palais-Cardinal, cujo arquiteto foi Jacques Lermercier. Da conjugação de todos estes efeitos resultava um espetáculo impressionante para "le plaisir des yeux" ${ }^{23}$. A cenografia "à italiana" torna-se um elemento importante de ilusionismo teatral que marca a «Ouverture» da Sala do Palais-Cardinal, não sem que Desmarets, sob o olhar do Cardeal e da Academia, deixe de cumprir as regras dramáticas essenciais e próprias à prática do verosímil.

21 Françoise Siguret, L'Oeil Surpris. Perception et représentation dans la première moitié du xvıle siècle, Paris, Klincksieck, 1993, p. 138.

22 "(...) la tragicomédie a permis la promotion d'une esthétique du plaisir, et d'un plaisir fédérateur, à la fois populaire et 'national'. Là reside sa grandeur et sa faiblesse.» (Baby, 2004, p. 303).

23 Leclerc, 1970, p. 26. 
Pela primeira vez em França, como fica claramente demonstrado por Hugh $\mathrm{Hall}^{24}$, e sob o protetorado de Richelieu, Desmarets de Saint-Sorlin encontrou solução para um dos maiores problemas contemporâneos da estética teatral, ao conjugar cenas de transformação com cenas unificadas: os movimentos do sol e da lua relativamente ao jardim de um palácio perto do mar, não só simbolizavam o rei e a rainha, presentes na estreia, mas também marcavam a passagem do tempo das vinte e quatro horas clássicas, reconciliando, pela primeira vez em França, o gosto barroco do espetáculo em mudança com a observância da regra da unidade de tempo. A cumplicidade política e estética que marca a relação entre Desmarets e o Cardeal reforçou o desejo deste de reabilitar o teatro (de que as Poéticas de La Mesnardière e de D’Aubignac dão conta) e devolve um sentido acrescido à encomenda de Mirame.

Basta entender, para tal, que a conceção da intriga e o cenário da peça se integram plenamente numa sala magnífica que permitia novos efeitos de representação e um inegável trompe l'oeil entre o palco e público/corte, sugerindo a multiplicação de palcos (do olhar): Richelieu, o rei e a rainha sentavam-se num estrado no meio da plateia; os espectadores convidados estavam instalados nas galerias ao longo da sala; o grupo de Richelieu estava em frente ao palco, no eixo da sua perspetiva; os cortesãos, com bilhetes individuais, foram colocados de acordo com os mestres do lugar. Estes contemplavam um duplo espetáculo: o do palco, a partir de um ângulo imperfeito; o da família real e do ministro que assistiam à representação teatral e serviam de intermediários entre o palco e as galerias. Richelieu, o rei e a rainha tornavam-se «spectateurs du pouvoir»" ${ }^{25}$, sendo a metonímia da ordem política representada nesta festa da corte, do palco para o público e do público para o palco que o acolhia como cenário. A composição, a representação e a edição de Mirame parece ter um único objetivo ${ }^{26}$ : o de afirmar o prestígio de Louis XIII face à Europa e o poder de Richelieu, tanto mais que o Cardeal acreditava que as artes cénicas acessórias eram garantia de sucesso nas peças dramáticas.

\footnotetext{
24 Hall, Hugh Gaston, Richelieu's Desmarets and the century of Louis XIV, Oxford, Clarendon Press, 1990.

25 Ver Jouhaud, 2000, p. 299 (descrição da recolha de testemunhos históricos).

26 Ver o Prefácio da edição de Catherine Guillot e Colette Scherer (p. 14).
} 
O êxito da peça de Desmarets de Saint Sorlin e de Richelieu foi de tal modo revelador de uma aliança entre o absolutismo e a festa teatral (e romanesca) que a Gazette lhe consagra um número especial - o no de 19 de janeiro de 1641 -, insistindo nitidamente, tanto no respeito pela unidade de tempo e de lugar, como nas decorações e nos jogos de luzes:

Pièce qui n'a pas eu sa pareille de notre age... sujet excellent, traité avec une telle abondance de pensées délicates, fortes et sublimes qu'il serait malaisé de trouver dans tout l'amas des plus belles tragédies de l'Antiquité les raisonnements qui sont dans cette seule pièce, ornée des plus nobles sentiments et des tendresses les plus grandes de l'amour. La France, et possible les pays étrangers n'ont jamais vu un plus magnifique théâtre \& dont la perspetive apportast plus de ravissement aux yeux des spectateurs... ${ }^{27}$.

A grandeza e o efeito datado da tragi-comédie centralizam-se na essência de um género, ao mesmo tempo popular e elitista, vulnerável e efémero como vunerável e efémera foi a reputação performativa de Desmarets de Saint-Sorlin: aos elogios imensos tecidos por Richelieu a Mirame, no momento da sua estreia, sucedeu-se um êxito medíocre que explica o facto de, nas representações posteriores, se ter juntado à peça um «ballet de rhinocéros» ${ }^{28}$. $\mathrm{O}$ "ravissement des yeux des spectateurs» a que alude a Gazette é forma de legitimar o seu êxito espetacular e pontual pelo efeito político. Mas é também forma de ler a alegoria do espetáculo que percorreu o Grand Siècle, síntese do prazer do irregular formal no regular ideológico e emblema da "douce influence» do poder sobre as artes e sobre as formas de arte mais efémeras que Georges Couton considera simbólicas escritas codificadas do/no século XviI ${ }^{29}$. Mirame torna-se o emblema brilhante dessa codificação e da codificação dos palcos do olhar no século de Louis Le Grand.

\footnotetext{
27 cit. em Georges Couton, Richelieu et le Théâtre, Lyon, Presses Universitaires de Lyon, 1986, p. 40.

28 Leclerc, 1970, p. 28.

29 Ver Couton, 1990.
} 